\title{
COMPOSIÇÃO DO LEITE DE CABRAS SAANEN INFECTADAS EXPERIMENTALMENTE COM Staphylococcus aureus E SUBMETIDAS A DOIS PROTOCOLOS DE TRATAMENTO
}

\section{MILK COMPOSITION OF SAANEN GOATS EXPERIMENTALLY INFECTED BY Staphylococcus aureus AND SUBJECTED TO TWO TREATMENT PROTOCOLS}

\author{
Rodolfo de Moraes Peixoto ${ }^{1 *}$ \\ Renata de Moraes Peixoto Araújo² \\ Luciana Jatobá e Silva Peixoto ${ }^{1}$ \\ Werônica Souza Rocha² \\ Maria da Conceição Aquino de Sá2 \\ Mateus Matiuzzi da Costa² \\ ${ }^{1}$ Instituto Federal de Educação, Ciência e Tecnologia do Sertão Pernambucano, Petrolina, PE, Brasil. \\ ${ }^{2}$ Universidade Federal do Vale do São Francisco, Petrolina, PE, Brasil. \\ *Autor para correspondência - rmpeixoto.vet@gmail.com
}

\section{Resumo:}

Neste estudo, objetivou-se avaliar a composição química do leite após a infecção e tratamento da mastite induzida por S. Aureus. Foram utilizadas 10 fêmeas caprinas da raça Saanen. Fez-se a infecção experimental em 20 glândulas mamárias, formando-se quatro grupos experimentais, sendo cada um composto por cinco glândulas mamárias. Um grupo foi tratado com antimicrobiano comercial e outro com pomada à base de extrato natural de planta. Os demais grupos foram constituídos controles. Os valores obtidos para gordura, lactose, proteína, sólidos totais e produção leiteira foram analisados ao longo dos momentos experimentais, comparando-os entre si e entre os grupos experimentais. A mastite foi diagnosticada 24 horas pós inoculação, utilizando-se a lactocultura. Os animais não apresentaram alterações nos parâmetros clínicos avaliados. Para os percentuais de gordura, proteína e sólidos totais, observou-se uma elevação ao longo dos momentos experimentais, sem variação entre os grupos experimentais. Tendo em vista a importância da terapia antimicrobiana convencional e a crescente utilização de antimicrobianos naturais, os resultados obtidos mostram igualdade entre as duas opções terapêuticas, principalmente no aspecto de manutenção dos principais componentes do leite.

Palavras-chave: cabras; composição do leite; terapia; mastite.

\begin{abstract}
:
This study aimed to evaluate the chemical composition of milk after infection and treatment of mastitis caused by Staphylococcus aureus. Ten Saanen goats were used. Experimental infection was performed in 20 mammary glands, forming four groups, each consisting of five mammary glands. One group was treated with commercial antimicrobial and another with natural plant extract-based ointment. The other groups were constituted as control. The values obtained for fat, lactose, protein, total solids, and milk production were analyzed through the experimental moments, comparing them among each other and between experimental groups. Mastitis was diagnosed by milk microbiology
\end{abstract}


after 24 hours of inoculation. The animals showed no changes in the clinical parameters evaluated. For the percentage of fat, protein, and total solids, there was an increase over the experimental moments. However, there was variation among the experimental groups. Given the importance of conventional antimicrobial therapy and the increased use of natural antimicrobials, obtained results showed equality between the two treatment options, especially regarding the maintenance of the main milk components.

Keywords: goat; milk composition; therapy; mastitis.

Enviado em: 04 julho 2015

Aceito em: 01 fevereiro 2016

\section{Introdução}

O efetivo caprino na região Nordeste brasileira representa mais de $90 \%$ do rebanho nacional ${ }^{(1)}$, sendo a produção leiteira uma importante fonte de renda para o produtor rural. Diversos fatores têm contribuído para melhoria da cadeia produtiva do leite de cabra; no entanto, ainda existem algumas limitações em decorrência dos poucos estudos voltados para composição do leite desta espécie. Os principais componentes utilizados na avaliação da qualidade da matéria-prima são: lactose, proteína, gordura e sólidos totais ${ }^{(2)}$.

Estudos com rebanhos caprinos leiteiros revelaram variação nos teores de gordura e proteínas no leite de diferentes raças ${ }^{(3-5)}$, em virtude de fatores genéticos, nutricionais, sistema de produção, fase da lactação, ano e estação do ano ${ }^{(2,6)}$. Níveis elevados da produção de leite foram associados com menor concentração de sólidos totais, em especial, teor de gordura. Estudos apontam que os teores de proteínas do leite não apresentam variação em diferentes períodos de lactação, mas a lactose e a gordura podem variar com o avanço da lactação ${ }^{(7,8)}$.

O componente material genético e o aporte de nutrientes também têm uma influência direta sobre a produção de leite e a concentração dos seus principais constituintes ${ }^{(8)}$. Além disso, têm-se os fatores relacionados à sanidade do rebanho, destacando-se a mastite, uma enfermidade frequente em rebanhos leiteiros e que traz uma série de prejuízos, dentre estes, a redução da produção leiteira e alteração dos principais componentes do leite ${ }^{(9-12)}$. Programas eficazes e econômicos de controle de mastite devem direcionar suas ações para as medidas preventivas, em virtude dos ganhos obtidos com a produção de leite; contudo, a intervenção terapêutica também constitui uma parte importante de um programa de controle de mastite ${ }^{(13)}$.

São escassos os estudos que avaliam a composição do leite após terapias antimicrobianas, principalmente a partir de extratos naturais. É sabido que a composição do leite é um importante requisito para se avaliar a qualidade do leite que será enviado à indústria de laticínios ${ }^{(2)}$.

Tendo em vista que o conhecimento da composição do leite é fundamental para a determinação de parâmetros qualitativos, além de definir propriedades organolépticas e industriais, realizou-se um este estudo com o objetivo de se avaliar a composição química do leite após a infecção com $S$. aureus e terapia antimicrobiana convencional e natural.

\section{Material e Métodos}

Foram utilizadas dez fêmeas caprinas da raça Saanen, com faixa etária variando entre 1,5 e 4 anos, 
entre primeira e segunda ordem de parto. Os animais estavam entre o sexto e nono mês de lactação, com produção leiteira variando entre 0,5 e 1,4 L/dia, sendo a média diária igual a 0,960 L. O período de adaptação dos animais às novas instalações da UNIVASF foi de oito meses. Todas as fêmeas foram negativas para a pesquisa de anticorpos anti-lentivírus da CAE, utilizando-se a imunodifusão em gel de agarose (IDGA). Antes da fase experimental, todas as fêmeas foram vermifugadas e submetidas ao casqueamento. Após o parto, as crias permaneceram em aleitamento natural durante três meses. As fêmeas foram submetidas à ordenha manual ( $1 \mathrm{x}$ ao dia).

O presente trabalho foi aprovado pelo Comitê de Ética em Estudos Humanos e Animais, da Universidade Federal do Vale do São Francisco, sob número de protocolo 0005/131211. Após a aprovação, desenhou-se o seguinte delineamento experimental para os estudos in vivo: foram formados quatro grupos, cada qual constituído por cinco glândulas mamárias. No grupo um (G1), as metades mamárias do lado direito foram infectadas e tratadas com pomada à base de extrato de Hymenaea martiana. A metade mamária esquerda do mesmo animal também foi infectada, porém foi considerada "controle" (não tratada), constituindo o grupo dois (G2). No grupo três (G3), as metades mamárias do lado direito foram infectadas e tratadas com antibiótico à base de gentamicina na metade direita. A metade mamária esquerda foi considerada "controle" (não tratada), sendo identificada como grupo quarto (G4). No total, fez-se a infecção experimental em 20 metades mamárias, em que cada grupo era composto por cinco metades mamárias. $\mathrm{O}$ fármaco utilizado foi determinado pelo teste de sensibilidade aos antimicrobianos. Antes da inoculação, foram estabelecidas as informações clínicas, as características físico-químicas e celulares do leite, mediante a realização de uma ordenha no período da manhã. Os animais foram negativos em três lactoculturas consecutivas, sendo adotado um intervalo de setes dias entre as coletas realizadas na fase pré-infecção. Para infecção experimental, utilizou-se uma cepa de campo oriunda de um caso de mastite subclínica em cabra e identificada de acordo com suas características bioquímicas ${ }^{(14)}$.

Após a obtenção dos índices das variáveis do momento inicial, as duas metades mamárias de cada fêmea foram infectadas, utilizando-se a via intramamária, por meio de uma sonda uretral $\mathrm{n}^{\circ} 4$ acoplada a uma seringa plástica estéril. Antes da inoculação, fez-se ordenha completa e anti-sepsia em ambos os tetos com álcool $70^{\circ} \mathrm{GL}$. Após a inoculação $(01 \mathrm{~mL})$, na parte proximal da cisterna, foi realizada massagem com movimentos ascendentes para o inóculo se distribuir na glândula mamária. A dose infectante utilizada foi de $1,2 \times 10^{8} \mathrm{UFC} / \mathrm{mL}$.

A partir deste instante os animais foram acompanhados diariamente, mediante avaliação clínica (temperatura retal, frequência cardíaca e respiratória e dinâmica ruminal) e análise do leite em uma ordenha diária ${ }^{(15)}$.

A mastite foi reconhecida no momento em que surgiram as evidências das alterações de características do leite, utilizando-se a lactocultura e o California Mastitis Test (CMT). Foram estabelecidos os seguintes momentos experimentais:

- M0 - anterior à infecção (0h);

- M1 - 48 horas pós infecção;

- M2 - 72 horas pós infecção/início do tratamento;

- M3 - 06 dias pós infecção/03 dias após o início tratamento;

- M4 - 09 dias pós infecção/final do tratamento;

- M5 - 12 dias pós infecção/06 dias após o final do tratamento;

- M6 - 25 dias pós infecção/16 dias após o final do tratamento;

- M7 - 41 dias pós infecção/32 dias após o final do tratamento;

O tratamento foi instituído 36 horas após a infecção. No G1, a metade mamária direita de cada fêmea foi tratada com pomada à base de $H$. martiana na dose de $05 \mathrm{~mL}$, via intramamária, durante seis dias consecutivos, logo após a ordenha da manhã. No G3, as metades mamárias foram tratadas com uma pomada comercial à base de gentamicina $(15 \mathrm{mg} / \mathrm{mL})$, via intramamária, durante seis dias 
consecutivos. Em cada animal, a metade mamária esquerda (grupos G2 e G4) foi considerada controle e recebeu solução fisiológica $(0,9 \% \mathrm{NaCl})$ na dose de $5 \mathrm{~mL}$.

Baseando em resultados de outros estudos, utilizou-se o extrato etanólico bruto da $H$. martiana para preparação da terapia intramamária ${ }^{(16,17)}$. Foram realizados testes de compatibilidade entre as diferentes bases e o extrato da planta. Realizaram-se testes de compatibilidade com as bases "creme" e "pomada", sendo observada a separação de fases quando utilizou-se a base creme. A partir daí, os testes seguiram com a base pomada. Observou-se, também, que os antimicrobianos comerciais têm em sua formulação de base "pomada". A pomada contendo extrato de $H$. martiana apresentou uma concentração final de 5\%.

Fórmula:

- Extrato de H. martiana (jatobá) ---------------- 2,5 g

- Lanolina ------------------------------------------ 15,0 g

- Vaselina sólida q.s.p. --------------------------- 50,0 g

Inicialmente, o extrato foi solubilizado em propilenoglicol. Em seguida, procedeu-se à manipulação da pomada com lanolina e vaselina, obtendo-se uma concentração final de lanolina de $30 \%$.

Para a determinação da composição do leite (gordura, proteína, lactose e sólidos totais), utilizou-se o espectrômetro FTIR - LactoScope FTIR Analyser, fabricado pela Delta Instruments, sendo empregado o método secundário de espectroscopia de infravermelho - Transformada de Fourier (FTIR).

Os valores obtidos para gordura, lactose, proteína, sólidos totais e produção leiteira foram analisados ao longo dos momentos experimentais, comparando-os entre si e entre os grupos experimentais, tendo a média como medida de tendência central, empregando-se os testes não paramétricos de Friedman para a comparação dos momentos dentro de cada grupo e de Kruskal-Wallis para a comparação dos grupos dentro de cada momento experimental.

\section{Resultados}

A mastite foi diagnosticada após 24 horas da inoculação, utilizando-se a lactocultura. Os animais não apresentaram alterações nos parâmetros clínicos avaliados.

$\mathrm{Na}$ avaliação dos componentes do leite, para gordura, observou-se maior percentual ao longo dos momentos experimentais em G1 e G2. No grupo tratado com antibiótico (G3) e seu respectivo controle (G4) não foram observadas alterações significativas. Este percentual não apresentou variação entre os grupos tratados e o controles (Tabela 1).

Para proteínas, também observou-se maior percentual ao longo dos momentos experimentais, sem variações entre os grupos (Tabela 2).

Para o percentual de lactose, não foram observadas variações ao longo dos momentos experimentais. Por outro lado, observou-se diferença entre os grupos, porém em apenas dois momentos (Tabela 3).

Para os sólidos totais, observou-se maior percentual ao longo dos momentos experimentais. Este percentual não apresentou variação entre os grupos tratados e o controle (Tabela 4).

Os dados obtidos no controle leiteiro demonstraram um decréscimo na produção em todos os grupos ao longo do período pós-infecção. Entre os grupos não foram observadas alterações significativas (Tabela 5). 
Tabela 1: Média de cinco repetições do teste de composição de leite para a variável percentual gordura em cabras infectadas experimentalmente com Staphylococcus aureus

\begin{tabular}{ccccccccc}
\hline & M0 & M1 & M2 & M3 & M4 & M5 & M6 & M7 \\
\hline G1 & $1,82^{\mathrm{Aa}}$ & $2,64^{\mathrm{ABa}}$ & $2,52^{\mathrm{ABa}}$ & $2,54^{\mathrm{ABa}}$ & $2,76^{\mathrm{ABa}}$ & $2,69^{\mathrm{ABa}}$ & $3,13^{\mathrm{Ba}}$ & $3,18^{\mathrm{Ba}}$ \\
G2 & $1,92^{\mathrm{Aa}}$ & $2,73^{\mathrm{ABa}}$ & $2,44^{\mathrm{ABa}}$ & $2,57^{\mathrm{ABa}}$ & $2,74^{\mathrm{ABa}}$ & $2,78^{\mathrm{ABa}}$ & $3,20^{\mathrm{Ba}}$ & $3,19^{\mathrm{Ba}}$ \\
G3 & $2,08^{\mathrm{Aa}}$ & $2,20^{\mathrm{Aa}}$ & $2,24^{\mathrm{Aa}}$ & $2,15^{\mathrm{Aa}}$ & $2,69^{\mathrm{Aa}}$ & $2,61^{\mathrm{Aa}}$ & $2,82^{\mathrm{Aa}}$ & $2,93^{\mathrm{Aa}}$ \\
G4 & $2,20^{\mathrm{Aa}}$ & $2,38^{\mathrm{Aa}}$ & $2,31^{\mathrm{Aa}}$ & $2,22^{\mathrm{Aa}}$ & $3,20^{\mathrm{Aa}}$ & $2,68^{\mathrm{Aa}}$ & $2,80^{\mathrm{Aa}}$ & $3,03^{\mathrm{Aa}}$ \\
\hline
\end{tabular}

G1: metades mamárias tratadas com extrato de H. martiana;

$\mathrm{G} 2$ : metades mamárias não tratadas;

G3: metades mamárias tratadas com antibiótico comercial à base de gentamicina;

G4: metades mamárias não tratadas;

Para cada grupo, valores seguidos por letras maiúsculas iguais não diferiram entre si $(\mathrm{P}>0,05)$;

Para cada momento, valores seguidos por letras minúsculas iguais não diferiram entre si $(P>0,05)$;

M0 - anterior à infecção (0h); M1 - 48 horas pós-infecção; M2 - 72 horas pós-infecção/início do tratamento; M3 - 06 dias pós-infecção/03 dias após início do tratamento; M4 - 09 dias pós-infecção/final do tratamento; M5 - 12 dias pósinfecção/03 dias após o final do tratamento; M6 - 25 dias pós-infecção/16 dias após o final tratamento; M7 - 41 dias pósinfecção/32 dias após o final do tratamento.

Tabela 2: Média de cinco repetições do teste de composição de leite para a variável percentual proteína em cabras infectadas experimentalmente com $S$. aureus

\begin{tabular}{ccccccccc}
\hline & M0 & M1 & M2 & M3 & M4 & M5 & M6 & M7 \\
\hline G1 & $2,88^{\mathrm{Aa}}$ & $3,30^{\mathrm{ABa}}$ & $3,32^{\mathrm{ABa}}$ & $3,40^{\mathrm{Ba}}$ & $3,32^{\mathrm{ABa}}$ & $3,27^{\mathrm{Ba}}$ & $3,03^{\mathrm{ABa}}$ & $3,08^{\mathrm{ABa}}$ \\
$\mathrm{G} 2$ & $2,87^{\mathrm{Aa}}$ & $3,22^{\mathrm{ABa}}$ & $3,13^{\mathrm{ABa}}$ & $3,22^{\mathrm{ABa}}$ & $3,20^{\mathrm{Ba}}$ & $3,23^{\mathrm{Ba}}$ & $3,03 \mathrm{ABa}$ & $3,08^{\mathrm{ABa}}$ \\
$\mathrm{G} 3$ & $3,06^{\mathrm{Aa}}$ & $3,27^{\mathrm{ABa}}$ & $3,21^{\mathrm{ABa}}$ & $3,21^{\mathrm{ABa}}$ & $3,41^{\mathrm{Ba}}$ & $3,43^{\mathrm{Ba}}$ & $3,21^{\mathrm{ABa}}$ & $3,19^{\mathrm{ABa}}$ \\
$\mathrm{G} 4$ & $3,05^{\mathrm{Aa}}$ & $3,24^{\mathrm{ABa}}$ & $3,19^{\mathrm{ABa}}$ & $3,24^{\mathrm{ABa}}$ & $3,63^{\mathrm{Ba}}$ & $3,39^{\mathrm{Ba}}$ & $3,21^{\mathrm{ABa}}$ & $3,17^{\mathrm{ABa}}$ \\
\hline
\end{tabular}

G1: metades mamárias tratadas com extrato de H. martiana;

G2: metades mamárias não tratadas;

G3: metades mamárias tratadas com antibiótico comercial à base de gentamicina;

$\mathrm{G} 4$ : metades mamárias não tratadas;

Para cada grupo, valores seguidos por letras maiúsculas iguais não diferiram entre si $(\mathrm{P}>0,05)$;

Para cada momento, valores seguidos por letras minúsculas iguais não diferiram entre si $(P>0,05)$;

M0 - anterior à infecção (0h); M1 - 48 horas pós-infecção; M2 - 72 horas pós-infecção/início do tratamento; M3 - 06 dias pós-infecção/03 dias após início do tratamento; M4 - 09 dias pós-infecção/final do tratamento; M5 - 12 dias pósinfecção/03 dias após o final do tratamento; M6 - 25 dias pós-infecção/16 dias após o final tratamento; M7 - 41 dias pósinfecção/32 dias após o final do tratamento.

Tabela 3: Média de cinco repetições do teste de composição de leite para a variável percentual lactose em cabras infectadas experimentalmente $\operatorname{com} S$. aureus

\begin{tabular}{ccccccccc}
\hline & M0 & M1 & M2 & M3 & M4 & M5 & M6 & M7 \\
\hline G1 & $4,29^{\mathrm{Aa}}$ & $4,03^{\mathrm{Aa}}$ & $4,05^{\mathrm{Aa}}$ & $3,87^{\mathrm{Aa}}$ & $4,08^{\mathrm{Aa}}$ & $4,10^{\mathrm{Aa}}$ & $4,30^{\mathrm{Aa}}$ & $4,16^{\mathrm{Aa}}$ \\
$\mathrm{G} 2$ & $4,30^{\mathrm{Aa}}$ & $4,13^{\mathrm{Aa}}$ & $4,22^{\mathrm{Aa}}$ & $4,23^{\mathrm{Aa}}$ & $4,38^{\mathrm{Aab}}$ & $4,16^{\mathrm{Aa}}$ & $4,34^{\mathrm{Aa}}$ & $4,16^{\mathrm{Aab}}$ \\
$\mathrm{G} 3$ & $4,43^{\mathrm{Aa}}$ & $4,32^{\mathrm{Aa}}$ & $4,29^{\mathrm{Aa}}$ & $4,39^{\mathrm{Aa}}$ & $4,56^{\mathrm{Ab}}$ & $4,36^{\mathrm{Aa}}$ & $4,41^{\mathrm{Aa}}$ & $4,42^{\mathrm{Aab}}$ \\
$\mathrm{G} 4$ & $4,47^{\mathrm{Aa}}$ & $4,37^{\mathrm{Aa}}$ & $4,34^{\mathrm{Aa}}$ & $4,39^{\mathrm{Aa}}$ & $4,54^{\mathrm{Aab}}$ & $4,41^{\mathrm{Aa}}$ & $4,45^{\mathrm{Aa}}$ & $4,44^{\mathrm{Ab}}$ \\
\hline
\end{tabular}

G1: metades mamárias tratadas com extrato de H. martiana;

$\mathrm{G} 2$ : metades mamárias não tratadas;

G3: metades mamárias tratadas com antibiótico comercial à base de gentamicina;

G4: metades mamárias não tratadas;

Para cada grupo, valores seguidos por letras maiúsculas iguais não diferiram entre si $(\mathrm{P}>0,05)$;

Para cada momento, valores seguidos por letras minúsculas iguais não diferiram entre si ( $\mathrm{P}>0,05)$;

M0 - anterior à infecção (0h); M1 - 48 horas pós-infecção; M2 - 72 horas pós-infecção/início do tratamento; M3 - 06 dias pós-infecção/03 dias após início do tratamento; M4 - 09 dias pós-infecção/final do tratamento; M5 - 12 dias pósinfecção/03 dias após o final do tratamento; M6 - 25 dias pós-infecção/16 dias após o final tratamento; M7 - 41 dias pósinfecção/32 dias após o final do tratamento. 
Tabela 4: Média de cinco repetições do teste de composição de leite para a variável percentual sólidos totais em cabras infectadas experimentalmente com $S$. aureus

\begin{tabular}{ccccccccc}
\hline & M0 & M1 & M2 & M3 & M4 & M5 & M6 & M7 \\
\hline G1 & $9,93^{\mathrm{Aa}}$ & $10,92^{\mathrm{ABa}}$ & $10,83^{\mathrm{ABa}}$ & $10,79^{\mathrm{ABa}}$ & $11,14^{\mathrm{ABa}}$ & $11,05^{\mathrm{ABa}}$ & $11,44^{\mathrm{Ba}}$ & $11,40^{\mathrm{Ba}}$ \\
$\mathrm{G} 2$ & $10,03^{\mathrm{Aa}}$ & $11,02^{\mathrm{ABa}}$ & $10,74^{\mathrm{ABa}}$ & $10,97^{\mathrm{ABa}}$ & $11,28^{\mathrm{Ba}}$ & $11,15^{\mathrm{ABa}}$ & $11,56^{\mathrm{Ba}}$ & $11,41^{\mathrm{Ba}}$ \\
G3 & $10,51^{\mathrm{Aa}}$ & $10,72^{\mathrm{Aa}}$ & $10,68^{\mathrm{Aa}}$ & $10,69^{\mathrm{Aa}}$ & $11,60^{\mathrm{Aa}}$ & $11,37^{\mathrm{Aa}}$ & $11,42^{\mathrm{Aa}}$ & $11,51^{\mathrm{Aa}}$ \\
$\mathrm{G} 4$ & $10,66^{\mathrm{Aa}}$ & $10,93^{\mathrm{Aa}}$ & $10,76^{\mathrm{Aa}}$ & $10,78^{\mathrm{Aa}}$ & $12,31^{\mathrm{Aa}}$ & $11,45^{\mathrm{Aa}}$ & $11,42^{\mathrm{Aa}}$ & $11,61^{\mathrm{Aa}}$ \\
\hline
\end{tabular}

G1: metades mamárias tratadas com extrato de H. martiana;

G2: metades mamárias não tratadas;

G3: metades mamárias tratadas com antibiótico comercial à base de gentamicina;

G4: metades mamárias não tratadas;

Para cada grupo, valores seguidos por letras maiúsculas iguais não diferiram entre si $(\mathrm{P}>0,05)$;

Para cada momento, valores seguidos por letras minúsculas iguais não diferiram entre si $(\mathrm{P}>0,05)$;

M0 - anterior à infecção (0h); M1 - 48 horas pós-infecção; M2 - 72 horas pós-infecção/início do tratamento; M3 - 06 dias pós-infecção/03 dias após início do tratamento; M4 - 09 dias pós-infecção/final do tratamento; M5 - 12 dias pósinfecção/03 dias após o final do tratamento; M6 - 25 dias pós-infecção/16 dias após o final tratamento; M7 - 41 dias pósinfecção/32 dias após o final do tratamento.

Tabela 5: Média de cinco repetições do controle leiteiro (L/dia) realizado em cabras infectadas experimentalmente com $S$. aureus

\begin{tabular}{ccccccccc}
\hline & $\mathrm{M} 0$ & $\mathrm{M} 1$ & $\mathrm{M} 2$ & $\mathrm{M} 3$ & $\mathrm{M} 4$ & $\mathrm{M} 5$ & $\mathrm{M} 6$ & $\mathrm{M} 7$ \\
\hline $\mathrm{G} 1 / \mathrm{G} 2$ & $0,94^{\mathrm{Ca}}$ & $0,78^{\mathrm{ABa}}$ & $0,74^{\mathrm{Aa}}$ & $0,83^{\mathrm{ABCa}}$ & $0,91^{\mathrm{BCa}}$ & $0,84^{\mathrm{ABCa}}$ & $0,81^{\mathrm{ABCa}}$ & $0,74^{\mathrm{Aa}}$ \\
$\mathrm{G} 3 / \mathrm{G} 4$ & $1,012^{\mathrm{Aa}}$ & $0,9^{\mathrm{Aa}}$ & $0,92^{\mathrm{Aa}}$ & $1,0^{\mathrm{Aa}}$ & $1,0^{\mathrm{Aa}}$ & $0,99^{\mathrm{Aa}}$ & $1,08^{\mathrm{Aa}}$ & $0,888^{\mathrm{Aa}}$ \\
\hline
\end{tabular}

G1: metades mamárias tratadas com extrato de H. martiana;

$\mathrm{G} 2$ : metades mamárias não tratadas;

G3: metades mamárias tratadas com antibiótico comercial à base de gentamicina;

G4: metades mamárias não tratadas;

Para cada grupo, valores seguidos por letras maiúsculas iguais não diferiram entre si $(\mathrm{P}>0,05)$;

Para cada momento, valores seguidos por letras minúsculas iguais não diferiram entre si $(\mathrm{P}>0,05)$;

M0 - anterior à infecção (0h); M1 - 48 horas pós-infecção; M2 - 72 horas pós-infecção/início do tratamento; M3 - 06 dias pós-infecção/03 dias após início do tratamento; M4 - 09 dias pós-infecção/final do tratamento; M5 - 12 dias pósinfecção/03 dias após o final do tratamento; M6 - 25 dias pós-infecção/16 dias após o final tratamento; M7 - 41 dias pósinfeç̧ão/32 dias após o final do tratamento.

\section{Discussão}

A utilização de antimicrobianos naturais na Medicina Veterinária vem crescendo, devido, principalmente, ao fenômeno da resistência aos antimicrobianos comerciais ${ }^{(18)}$. O potencial antimicrobiano de extratos de plantas do gênero Hymenaea já foi comprovado em alguns estudos ${ }^{(16,19)}$, em função da presença de flavonoides e terpenos ${ }^{(17)}$.

É sabido que a mastite é um dos principais fatores que afetam a composição e qualidade do leite enviado à indústria de laticínios, sendo o Staphylococcus aureus um dos patógenos mais importantes da mastite em fêmeas caprinas ${ }^{(20)}$. Além disso, a realização do presente delineamento experimental foi motivada pela ausência de informações acerca da estabilidade das concentrações dos principais constituintes do leite de cabras, após a infecção e terapia com extratos naturais e fármacos comerciais.

Observou-se aumento nos teores de gordura, proteína e sólidos totais, logo no primeiro momento pós infecção experimental (M1). No entanto, incrementos não foram observados ao longo dos demais 
momentos. Quanto à comparação dos grupos em cada momento experimental, não foram observadas variações, à exceção da variável lactose que apresentou maior percentual no grupo tratado com antibiótico comercial (G3), quando comparado ao grupo tratado com o antimicrobiano natural (G1) ao final da terapia (M4). No momento sete (32 dias após término da terapia) menor percentual de lactose também foi observado para o grupo tratado com $H$. martiana quando comparado com o controle. Estes resultados não diferiram daqueles encontrados por Vilanova et al. ${ }^{(21)}$, em trabalho realizado com a mesma raça e período de lactação similar, porém com animais negativos para a mastite.

Isto indica que estes fatores não foram afetados pela inoculação experimental dos animais com o S. aureus. De modo geral, as inferências acerca das variações dos principais componentes do leite devem ser feitas com bastante cautela, em virtude da existência de outras variáveis que influenciam o percentual destes constituintes no leite, tais como genética, manejo alimentar, regime de ordenha, estágio de lactação e ordem de parto $^{(21-23)}$.

Para os constituintes gordura, proteína e sólidos totais pesquisados, não foram observadas alterações entre os grupos tratados com a pomada à base de H. martiana e o grupo que recebeu antimicrobiano comercial, corroborando com os achados de Karzis et al. ${ }^{(10)}$. Esses autores, realizando um estudo similar em cabras leiteiras, não observaram diferenças estatisticamente significativas nos percentuais de gordura, proteína e lactose antes, durante e após o tratamento com antibióticos. Isto constitui um achando relevante, uma vez que vários grupos de pesquisa estão desenvolvendo estudos com antimicrobianos naturais, dada a elevada resistência dos patógenos envolvidos na mastite aos diversos antimicrobianos comerciais e a preservação das características do leite após a terapia com extrato natural constitui um aspecto relevante.

Neste estudo, a concentração média de gordura aumentou imediatamente após a infecção. Ma et al. ${ }^{(24)}$ e Ogola et al. ${ }^{(25)}$ também observaram aumento de ácidos graxos durante os processos infecciosos da mastite. Leitner et al. ${ }^{(26)}$ realizaram estudos sobre a mastite subclínica em ovinos e observaram que a percentagem de gordura era mais baixa em glândulas não infectadas do que nas infectadas, atribuindo esta alteração à redução no volume de leite. O aumento na concentração de ácidos graxos afeta negativamente as características sensoriais como sabor, odor e cor ${ }^{(27)}$, além de afetar outras propriedades tecnológicas, tais como a estabilidade durante a armazenagem ${ }^{(28)}$.

Para o percentual de lactose, não foram observadas variações ao longo dos momentos experimentais. Outros autores demonstraram a redução dos teores de lactose após a mastite infecciosa ${ }^{(12)}$, devido à injúria no tecido mamário. De modo geral, a lactose é considerada um dos nutrientes mais estáveis na composição química do leite, estando diretamente relacionada à regulação da pressão osmótica, de modo que uma maior produção de lactose determina maior produção de leite ${ }^{(23)}$.

Com relação aos dados do controle leiteiro, não foram observadas alterações entre os grupos experimentais. Por outro lado, observou-se um decréscimo na produção de leite oriunda dos animais que formaram os grupos G1 e G2 (tratados com a pomada de H martiana e controle, respectivamente), sendo este um achado comum durante o curso das infecções intramamárias, em decorrência das alterações na fisiologia da glândula mamária, resultando, por conseguinte, na diminuição na produção de leite e modificações na composição do leite ${ }^{(12)}$. Contudo, tendo em vista que não houve variação da produção de leite entre os quatro grupos, a redução da produção em G1 e G2 ao longo dos momentos experimentais pode estar relacionada ao fator animal.

\section{Conclusões}

Os trabalhos acerca das alterações que ocorrem na composição do leite de cabras fornecem informações 
importantes sobre o processo infeccioso da mastite e podem revelar-se bons bioindicadores da doença. Observou-se aumento das concentrações de gordura, proteína e sólidos totais após a infecção experimental, mantendo-se constante antes, durante e após a terapia. A ausência de diferenças para os percentuais dos principais constituintes do leite entre os grupos experimentais (pomada a base de H. martiana, antimicrobiano comercial e controles) avaliados constitui um achado relevante, dada a quantidade de estudos conduzidos na área de produtos naturais. Este estudo demonstra a possibilidade do uso de terapias alternativas sem o comprometimento de parâmetros que são utilizados pela indústria de laticínios.

\section{Agradecimentos}

À FACEPE pela concessão da bolsa de pós-graduação e ao MCT-INSA/CNPq pelo auxílio financeiro na compra de materiais e equipamentos utilizados nesta Pesquisa, via projeto aprovado no edital MCT-INSA/CNPq/CT-Hidro/Ação Tranversal Nº 35/2010.

\section{Referências}

1.IBGE. Sistema IBGE de Recuperação Automática - SIDRA. 2012. Disponível em: http://www.sidra.ibge. gov.br. Acesso em 24 de março de 2014.

2.Souza GN, Brito JRF, Brito MAVP, Lange C, Faria CG, Moraes LCD, Fonseca RG, Silva YA. Composition and bulk tank somatic cell counts of milk from dairy goat herds in Southeastern Brazil. Brazilian Journal of Veterinary Research and Animal Science, São Paulo, 2009;46(1):19-24. Disponível em:

http://dx.doi.org/10.1590/S1413-95962009000100003. Acesso em 20 de abril de 2014.

3.Haenlein GFW. Status and prospects of the dairy goat industry in the United States. Journal of Animal Science. 1996;74(5):1173-1181.

4.Zeng SS, Escobar EN. Effect of breed and milking method on somatic cell count, standard plate count and composition of goat milk. Small Ruminant Research. 1996;19(2):169-175. Disponível em:

http://dx.doi.org/10.1016/0921-4488(95)00744-X. Acesso em 20 de abril de 2014.

5.Sung YY, Wu TI, Wang PH. Evaluation of milk quality of Alpine, Nubian, Saanen and Toggenburg breeds in Taiwan. Small Ruminant Research. 1999;33(1):17-23. Disponível em:

http://dx.doi.org/10.1016/S0921-4488(98)00201-6. Acesso em 20 de abril de 2014.

6.Morgan F, Massouras T, Barbosa M, Roseiro L, Ravasco F, Kandarakis I, Bonnin V, Fistakoris M, Anifantakis E, Jaubert G, Raynal-Ljutovac K. Characteristics of goat milk collected from small and medium enterprises in Greece, Portugal and France. Small Ruminant Research. 2003;47(1)39-49. Disponível em: http://dx.doi. org/10.1016/S0921-4488(02)00252-3. Acesso em 22 de abril de 2014.

7.Das M, Singh M. Variation in blood leucocytes, somatic cell count, yield and composition of milk of crossbred goats. Small Ruminant Research. 2000;35(2):169-174.

8.Prasad H, Sengar OPS. Milk yield and composition of the Barbari goat breed and its crosses with Jamunapari, Beetal and Black Bengal. Small Ruminant Research. 2002;45(1):79-83. Disponível em: http://dx.doi. org/10.1016/S0921-4488(02)00112-8. Acesso em 22 de abril de 2014. 
9.Leitner G, Merin EU, Silanikove N. Changes in milk composition as affected by subclinical mastitis in goats. Journal of Dairy Science. 2004;87(6):1719-1726. Disponível em: http://dx.doi.org/10.3168/jds.S00220302(04)73325-1. Acesso em 22 de abril de 2014.

10.Karzis J, Donkin EF, Petzer I.M. Intramammary antibiotics in dairy goats: effect of stage of lactation, parity and milk volume on withdrawal periods, and the effect of treatment on milk compositional quality. Onderstepoort Journal of Veterinary Research. 2007;74(3):243-249.

11.Koop G, Van Werven T, Schuilinh HJ, Nielen M. The effect of subclinical mastitis on milk yield in dairy goats. Journal of Dairy Science. 2010;93(12):5809-5817. Disponível em: http://dx.doi.org/10.3168/jds.20103544. Acesso em 22 de abril de 2014.

12.Mungatana NK, Ngure RM, Shitandi A, Onyiego B, Mutumba M. Effect of experimental Staphylococcus aureus mastitis on compositional quality of goat milk. International Journal of Dairy Technology. 2011;64(3):360364. Disponível em: http:// 10.1111/j.1471-0307.2011.00672.x. Acesso em 22 de abril de 2014.

13.Erskine RJ, Wagner S, Degraves FJ. Mastitis therapy and pharmacology. The Veterinary Clinics of Noth America. Food Animal Practice. 2003;19(1):109-138.

14.Holt JG. Bergey's manual of determinative bacteriology. $9^{a}$.ed. Baltimore: Williams \& Wilkins. 1994.

15.Santos RA, Mendonça CL, Afonso JAB, Simão LCV. Aspectos clínicos e características do leite em ovelhas com mastite induzida experimentalmente com Staphylococcus aureus. Pesquisa Veterinária Brasileira, Rio de Janeiro. 2007;27(1)6-12. Disponível em: http://dx.doi.org/10.1590/S0100-736X2007000100002. Acesso em 22 de abril de 2014.

16.Gonçalves AL, Alves Filho A, Menezes H. Estudo comparativo da atividade antimicrobiana de extratos de algumas árvores nativas. Arquivos do Instituto Biológico, São Paulo. 2005;72(3)353-358. Disponível em: http://www.biologico.sp.gov.br/docs/arq/V72_3/goncalves.PDF. Acesso em 22 de abril de 2014.

17.Cruz Silva MEG, Guimarães AL, Oliveira AP, Araújo CZ, Siqueira Filho JA, FONTANA AP, Damasceno PKF, Branco CRC, Branco A, Almeida JRGS. HPLC-DAD analysis and antioxidant activity of Hymenaea martiana Hayne (Fabaceae). Journal of Chemical and Pharmaceutical Research. 2012;4(2):1160-1166. Disponível em: http://jocpr.com/vol4-iss2-2012/JCPR-2012-4-2-1160-1166.pdf. Acesso em 22 de abril de 2014.

18.Schuch LFD, Wiest JM, Coimbra HS, Prestes LS, Toni L, Lemos JS. Cinética da atividade antibacteriana in vitro de extratos naturais frente a micro-organismos relacionados à mastite bovina. Ciência Animal Brasileira, Goiás, 2008;9(1):161-169. Disponível em: http://www.revistas.ufg.br/index.php/vet/article/view/968/3442. Acesso em 22 de abril de 2014.

19.Fernandes TT, Santos ATF, Pimenta FC. Atividade antimicrobiana das plantas - Plathymenia reticulate, Hymenaea courbaril e Guazuma ulmifolia. Revista de Patologia Tropical. 2005;34(2):113-122. Disponível em: https://repositorio.bc.ufg.br/bitstream/ri/163/1/atividade\%20amicrobiana.pdf. Acesso em 22 de abril de 2014.

20.Shearer JK, Harris J. Mastitis in dairy goats. University of Florida. 2003;85:1-7. Disponível em: http:// www.georgiagoat.com/articles/Mastitis.pdf. Acesso em 22 de abril de 2014.

21.Vilanova MS, Gonçalves M, Osório MTM, Esteves RMG, Schmidt V. Aspectos sanitários do úbere e composição química do leite de cabras saanen. Acta Scientiae Veterinariae, Rio Grande do Sul. 2008;36(3):235240. Disponível em: http://www.lume.ufrgs.br/handle/10183/20718. Acesso em 22 de abril de 2014.

22.Aganga AA, Amarteifio JO, Nkile N. Effect of stage of lactation on nutrient composition of Tswana sheep and goat's milk. Journal of Food Composition and Analylis. 2002;15(5):533-543. Disponível em: http://www. 
sciencedirect.com/science/article/pii/S0889157502910616. Acesso em 22 de abril de 2014.

23.Queiroga RCRE, Costa RG, Biscontini TMB, Medeiros AN, Madruga MS, Schuler ARP. Influência do manejo do rebanho, das condições higiênicas da ordenha e da fase de lactação na composição química do leite de cabras Saanen. Revista Brasileira de Zootecnia, Viçosa. 2007;36(2):430-437. Disponível em: http://dx.doi. org/10.1590/S1516-35982007000200021. Acesso em 22 de abril de 2014.

24.Ma Y, Ryan C, Barbano DM, Galton DM, Rudan MA, Boor KJ. Effects of somatic cell count on quality and shelf-life of pasteurized fluid milk. Journal of Dairy Science. 2003;83(2):264-274. Disponível em: http:// dx.doi.org/10.3168/jds.S0022-0302(00)74873-9. Acesso em 22 de abril de 2014.

25.Ogola H, Shitandi A, Nanua J. Effect of mastitis on raw milk compositional quality. Journal of Veterinary Science. 2007;8(3):237-242. Disponível em http://dx.doi.org/10.4142/jvs.2007.8.3.237. Acesso em 22 de abril de 2014.

26.Leitner G, Chaffer M, Caraso Y, Ezra E, Kababea D, Winkler M, Glickman A, Saran A. Udder infection and milk somatic cell count, NAGase activity and milk composition - fat, protein and lactose- in Israeli-Assaf and Awassi sheep. Small Ruminant Research. 2003;49(2):157-164. Disponível http://dx.doi.org/10.1016/S09214488(03)00079-8. Acesso em 22 de abril de 2014.

27.Park YW, Juárez M, Ramos M, Haenlein GFW. Physico-chemical characteristics of goat and sheep milk. Small Ruminant Research. 2007. 68(1-2):88-113. Disponível em http://dx.doi.org/10.1016/j. smallrumres.2006.09.013. Acesso em 22 de abril de 2014.

28.Slacanac V, Bozanic R, Hardi J, Szabó JR, Lucan M, Krstanovic V. Nutritional and therapeutic value of fermented caprine milk. International Journal of Dairy Technology. 2010;63(2):171-189. Disponível http:// doi/10.1111/j.1471-0307.2010.00575.x/full. Acesso em 22 de abril de 2014. 